\title{
Microbial composting of fruit tree wastes through controlled submerged fermentation
}

\author{
Marian Petre, ${ }^{1}$ Violeta Petre, ${ }^{2}$ Ionela Rusea ${ }^{1}$ \\ ${ }^{1}$ University of Pitesti; ${ }^{2}$ University of Agronomic Sciences and Veterinary Medicine, \\ Bucharest, Romania
}

\begin{abstract}
The ecological valorising of organic compounds represented by many derived wastes from fruit processing through the controlled microbial composting was established as the main aim of research experiments presented in this paper. There were carried out laboratory works to test the optimal needs of bacterial and fungal pure cultures to grow inside different marc made of apple, cherry and plum wastes (chemical composition, temperature, $\mathrm{pH}$, oxygen/carbon dioxide concentration). In this respect, there were used pure bacterial cultures of Bacillus genus as well as the fungal ones belonging to species of Pleurotus for microbial transformation of different fruit wastes. The biotechnology of microbial composting was applied by using a laboratory-scale bioreactor of $15 \mathrm{~L}$ working volume. The submerged fermentations of different fruit wastes were set up for the following parameters: constant temperature, $23^{\circ} \mathrm{C}$; agitation speed, 80-100 rev. min $^{-1}$; $\mathrm{pH}$ level, 5.7-6.0 units; dissolved oxygen tension within the range of $30-70 \%$. After a period of $140-230 \mathrm{~h}$, the fermented composts, containing the microbial biomass developed through biochemical transforming of marc into natural fertilisers, were produced.
\end{abstract}

Correspondence: Marian Petre, University of Pitesti, 1 Targul din Vale Street, 110040, Pitesti, Romania.

Tel.: +40348.45.31.02 - Fax: +40348.45.31.23.

E-mail: marian_petre_ro@yahoo.com

Key words: bacteria, composting, fruit tree wastes, mushrooms, submerged fermentation.

Funding: this research work was carried out in the frame work of the Project No. 201/28.10.2013 funded through the Research Program Innovation Subprogram Checks of Innovation from the National Programme of Research and Development 2007-2013.

Conference presentation: Meeting on Environmental Sustainability and Food Security, Potenza, Italy, 2014.

Received for publication: 3 July 2014.

Revision received: 5 September 2014.

Accepted for publication: 5 September 2014.

(C) Copyright M. Petre et al., 2014

Licensee PAGEPress, Italy

Italian Journal of Agronomy 2014; 9:610

doi:10.4081/ija.2014.610

This article is distributed under the terms of the Creative Commons Attribution Noncommercial License (by-nc 3.0) which permits any noncommercial use, distribution, and reproduction in any medium, provided the original author(s) and source are credited.

\section{Introduction}

An efficient method to convert cellulose materials, in order to produce unconventional high-calorie foods or feeds, is the direct conversion through the controlled metabolism of cellulolytic microorganisms. Theoretically, any microorganism that can grow in the shape of pure culture on cellulosic substrates, using them as carbon and energy sources, should be considered a potential organism for single-cell protein or protein rich feed producing (Chahal and Hachey, 1990).

In the last decades, many researches were done to biodegrade and convert different cellulosic wastes into useful products by microbial composting with bacterial and fungal species through their specific metabolism (Verstraete and Top, 1992; Beguin and Aubert, 1994; Moser, 1994; Carlile and Watkinson, 1996).

In this respect, one of the most efficient biotechnological method to convert the cellulosic wastes resulted alcoholic distillation of fermented fruit tree wastes, such as juice and pulps of apples, pears and plums, is their controlled submerged fermentation through the enzymatic activity of bacterial cells and edible mushroom mycelia by using automatic biotechnological devices to get nutritive microbial biomass through controlled composting of the fruit tree wastes to be used as natural bio-fertilisers of horticultural crops (Petre and Petre, 2013).

The main purpose of this work consists in testing the completely new biotechnology for controlled composting of different liquid wastes of tree fruits through the submerged cultivation of bacterial cells and edible mushroom species in order to get high nutritive organic fertilisers in a very short time of producing cycle. This original biotechnology has already been registered at Romanian Office of Patents and Trade Marks.

\section{Materials and methods}

\section{Microorganisms and culture media}

According to the main aim of this work, there were tested two cellulolytic microorganisms, namely the bacterial species Bacillus subtilis and the fungal one, respectively, Pleurotus ostreatus (Jacquin ex Fries) Kummer from the cultures collection of University of Pitesti.

B. subtilis was isolated from the apple wastes resulted from alcoholic distilleries and was maintained in culture medium containing $(\mathrm{g} / \mathrm{L})$ : peptone 5.0; meat extract 3.0 and agar 2.0. The medium was autoclaved at $121^{\circ} \mathrm{C}$ for $15 \mathrm{~min}$. The cultures were kept at $4^{\circ} \mathrm{C}$ and renewed every 45 days. The seed culture medium was composed by 100 $\mathrm{g} / \mathrm{L}$ of sucrose (1\%) and $\mathrm{NaCl}(0.5 \%)$.

The edible mushroom $P$. ostreatus was used as pure culture in all carried out experiments. The stock cultures were maintained on maltextract agar (MEA) slants. Slants were incubated at $25^{\circ} \mathrm{C}$ for $5-7 \mathrm{~d}$ and then stored at $4^{\circ} \mathrm{C}$. The mushroom cultures used as inoculum for the 
cultivation inside the culture vessel of laboratory-scale bioreactor were grown in 250-mL flasks containing $100 \mathrm{~mL}$ of MEA medium (20\% malt extract, $2 \%$ yeast extract, $20 \%$ agar-agar) at $23^{\circ} \mathrm{C}$ on rotary shaker incubators at 110 rev min $^{-1}$ for 5-7 d (Ropars et al., 1992; Wainwright, 1992; Smith, 1998).

The natural substrates for the controlled microbial composting were prepared from different sorts of organic fruit wastes such as juices and pulps, resulted from the industrial processing through alcohol distillation of fermented apples, pears and plums. These substrates were made by apple and plum wastes resulted from alcohol distillation mixed with other needed natural ingredients, such as, barley and wheat bran, in small amounts (1.5-3\% w/w), in order to improve the enzymatic activity of bacterial and mushroom mycelia and convert the cellulose content of these fruit wastes into protein biomass.

The culture medium composition for microbial conversion and protein synthesis was made of apple wastes $50 \%$, previously treated by mixing with wheat bran $10 \%$, barley bran $5 \%$, d-glucose $5 \%$ and hydrated with pure water $30 \%$. This was the first variant of culture substrate for mushroom growing (substrate 1). The second variant composition of culture substrate was prepared from plum wastes $50 \%$ improved by adding barley bran $10 \%$, wheat bran $5 \%$, d-glucose $5 \%$ and tap water $30 \%$ (substrate 2). The two variants of culture substrates were used in experiments for growing both monocultures and co-cultures of $B$. subtilis and $P$. ostreatus. In this respect, the optimal temperatures during the growth of bacterial and mycelial co-cultures were registered between $23-25^{\circ} \mathrm{C}$ corresponding to initial $\mathrm{pH}$ levels of $4.5-6.0$. The agitation speed was tested in the range of 30-90 rpm (Beguin and Aubert, 1994).

\section{Methods used in experiments}

The microbial strains of $B$. subtilis and $P$. ostreatus were used in pairs as well as separately to compare the efficiency of their biological potential in bioconversion of fruit wastes into protein biomass (Petre and Petre, 2013).

These strains were tested both in monocultures and co-cultures for growing on two variants of culture substrates made of apple and plum wastes mixed with cereal wastes. The medium composition, $\mathrm{pH}$ levels, incubation temperature, agitation rate, inoculum age as well as inoculum volume during the submerged co-fermentation were registered as significant physical and chemical factors that could influence the bioconversion of fruit wastes used as growth substrates into protein biomass as well as microbial biomass formation (Ropars et al., 1992; Chahal, 1994; Lamar et al., 1992).

Bioconversion of apple and plum wastes requires a suitable environment for growth of pure bacterial and fungal cultures, in order to increase efficiency of submerged fermentation made by mono- and cocultures of $B$. subtilis and $P$. ostreatus (Petre and Petre, 2012; Smith, 1998; Stamets, 1993; Leahy and Colwell, 1990).

All the cultivation substrates were steam sterilised at $123^{\circ} \mathrm{C}$ for 30 min at $1.2 \mathrm{~atm}$ inside the culture vessel of the bioreactor and after cooling, the substrates from the glass vessel were inoculated aseptically with the seed cultures grown in the rotary shaker incubator as it was previously described.

The steam sterilisation of the substrates for bacterial and fungal growing is compulsory because all these liquid wastes are contaminated with competitive and opportunistic microbial species, many of them being phytopatogenic. In this way, even the energy expenses were registered between $5-10 \%$ from the final price of the bio-fertilisers, the effectiveness cost justifies this physical treatment to eliminate the competitors on the same substrates made of fruit wastes to be converted in a nutritive biomass. After inoculation into the bioreactor vessel, the submerged fermentation was set up at the following parameters: constant temperature, $23^{\circ} \mathrm{C}$; agitation speed, $80-100 \mathrm{rev} . \mathrm{min}^{-1}$; $\mathrm{pH}$ level, 5.7-6.0 units; dissolved oxygen tension within the range of 30$70 \%$. The mushroom growing cycle lasted from 7 to 10 days, depending on cultivated species, and there were registered thousands of mushroom pellets with variable dimensions that were developed inside the culture vessel of the laboratory-scale bioreactor as it is presented in Figure 1.

The design of this bioreactor incorporates a device to keep the constant temperature, an inoculum reservoir, a sterile air supply device in aerobic processes, a culture vessel as well as an automation panel for bioprocess monitoring and management (Petre and Petre, 2013).

The content of reducing sugars was determined by Kubicek technique and the total nitrogen content was analysed by Kjeldahl method (Glazebrook et al., 1992; Chahal and Hachey, 1990). The experimental data determined as total reducing sugars contents (Kubicek et al., 1993) were correlated by complementary investigations with those values of dry weight loss measurements of fruit wastes bioconversion, for both mono- and co-cultures of $B$. subtilis and $P$. ostreatus.

\section{Results}

During the whole bioconversion of apple and plum wastes as juices and pulps from alcohol distillation $48 \mathrm{~h}$ samples were collected and then chemically analysed to assess the progress of total reducing sugars as well as total nitrogen contents during bioconversion of apple and plum wastes into protein biomass by using monocultures and co-cultures of $B$. subtilis and $P$. ostreatus are presented in Tables 1 and 2.

The progress of dry weight loss of the same fruit wastes used as substrates for microbial cultures is shown in Table 3.

Finally, after $720 \mathrm{~h}$ of submerged fermentation the protein biomass obtained through bioconversion of apple and plum wastes by using the co-cultures of $B$. subtilis and $P$. ostreatus was collected from the culture vessel of laboratory scale bioreactor as it is shown in Figures 2 and 3.

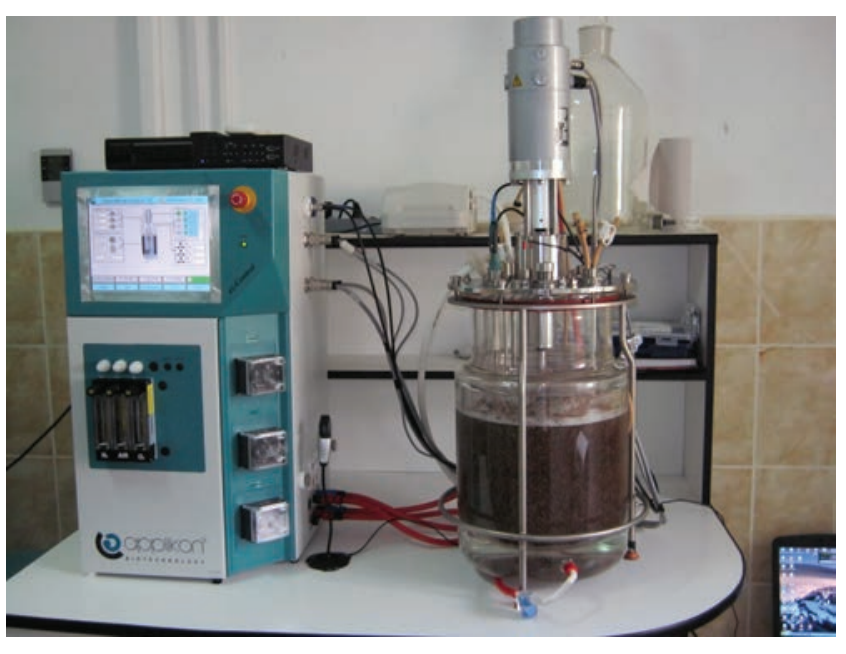

Figure 1. The laboratory-scale bioreactor for submerged cultivation of microbial cells. 
Table 1. Total reducing sugars during bioconversion of apple and plum wastes.

\begin{tabular}{|c|c|c|c|c|c|c|}
\hline \multirow[t]{3}{*}{ Time (h) } & \multicolumn{6}{|c|}{ Total reducing sugars (mg/g)* } \\
\hline & \multicolumn{2}{|c|}{$\begin{array}{l}\text { B. subtilis } \\
\text { (monoculture) }\end{array}$} & \multicolumn{2}{|c|}{$\begin{array}{l}\text { P. ostreatus } \\
\text { (monoculture) }\end{array}$} & \multicolumn{2}{|c|}{$\begin{array}{c}\text { B. subtilis - P. ostreatus } \\
\text { (co-cultures) }\end{array}$} \\
\hline & Substrate 1 & Substrate 2 & Substrate 1 & Substrate 2 & Substrate 1 & Substrate 2 \\
\hline 72 & 2.10 & 2.80 & 4.50 & 6.90 & 9.30 & 12.80 \\
\hline 144 & 4.10 & 4.90 & 5.80 & 8.10 & 11.10 & 15.50 \\
\hline 216 & 5.70 & 6.80 & 7.90 & 10.40 & 14.90 & 18.30 \\
\hline 288 & 7.80 & 8.10 & 10.70 & 12.80 & 18.30 & 21.80 \\
\hline 360 & 9.50 & 10.90 & 14.10 & 15.50 & 21.90 & 25.30 \\
\hline 432 & 10.70 & 12.50 & 16.30 & 18.20 & 24.50 & 27.50 \\
\hline 504 & 11.45 & 15.30 & 19.70 & 21.50 & 26.30 & 30.10 \\
\hline 576 & 12.50 & 17.70 & 21.80 & 23.30 & 28.80 & 32.50 \\
\hline 648 & 14.80 & 19.30 & 23.50 & 25.80 & 30.10 & 33.90 \\
\hline 720 & 14.90 & 19.50 & 23.10 & 25.30 & 30.50 & 33.10 \\
\hline
\end{tabular}

*All data are representative as means of three repeated determinations.

Table 2. Total nitrogen content during bioconversion of apple and plum wastes.

\begin{tabular}{|c|c|c|c|c|c|c|}
\hline \multirow[t]{3}{*}{ Time (h) } & \multicolumn{6}{|c|}{ Total nitrogen content of fungal protein biomass ( $\mathrm{g} \%$ dry weight)* } \\
\hline & \multicolumn{2}{|c|}{$\begin{array}{l}\text { B. subtilis } \\
\text { (monoculture) }\end{array}$} & \multicolumn{2}{|c|}{$\begin{array}{l}\text { P. ostreatus } \\
\text { (monoculture) }\end{array}$} & \multicolumn{2}{|c|}{$\begin{array}{c}\text { B. subtilis - P. ostreatus } \\
\text { (co-cultures) }\end{array}$} \\
\hline & Substrate 1 & Substrate 2 & Substrate 1 & Substrate 2 & Substrate 1 & Substrate 2 \\
\hline 72 & 3.50 & 3.90 & 4.50 & 5.10 & 7.90 & 9.50 \\
\hline 144 & 4.10 & 4.75 & 5.80 & 6.40 & 9.30 & 12.10 \\
\hline 216 & 5.70 & 6.55 & 7.70 & 8.50 & 14.10 & 15.80 \\
\hline 288 & 7.80 & 7.90 & 9.80 & 10.10 & 15.80 & 18.10 \\
\hline 360 & 9.50 & 9.80 & 12.10 & 12.50 & 18.30 & 21.90 \\
\hline 432 & 10.70 & 11.10 & 14.00 & 14.40 & 21.50 & 23.30 \\
\hline 504 & 11.45 & 12.70 & 16.70 & 17.30 & 23.60 & 25.70 \\
\hline 576 & 12.10 & 13.50 & 18.50 & 20.10 & 25.90 & 27.10 \\
\hline 648 & 12.80 & 14.30 & 20.80 & 21.80 & 27.20 & 28.90 \\
\hline 720 & 12.70 & 14.10 & 20.30 & 21.50 & 27.10 & 28.30 \\
\hline
\end{tabular}

*All data are representative as means of three repeated determinations.

Table 3. Dry weight loss of apple and plum wastes used for microbial composting.

\begin{tabular}{|c|c|c|c|c|c|c|}
\hline \multirow[t]{2}{*}{ Time (h) } & & $\begin{array}{l}\text { is } \\
\text { ure) }\end{array}$ & $\begin{array}{l}\text { Dry w } \\
\text { P. os } \\
\text { (mon }\end{array}$ & $\begin{array}{l}\text { loss }(g \%) * \\
\text { us } \\
\text { ure) }\end{array}$ & \multicolumn{2}{|c|}{$\begin{array}{c}\text { B. subtilis - P. ostreatus } \\
\text { (co-cultures) }\end{array}$} \\
\hline & Substrate 1 & Substrate 2 & Substrate 1 & Substrate 2 & Substrate 1 & Substrate 2 \\
\hline 72 & 2.50 & 4.30 & 5.10 & 6.40 & 7.30 & 10.40 \\
\hline 144 & 3.10 & 5.50 & 5.90 & 7.00 & 8.50 & 12.80 \\
\hline 216 & 3.90 & 6.70 & 6.70 & 8.50 & 9.70 & 14.10 \\
\hline 288 & 4.80 & 7.90 & 7.90 & 9.40 & 10.80 & 15.30 \\
\hline 360 & 5.50 & 8.80 & 8.80 & 10.50 & 12.50 & 16.50 \\
\hline 432 & 6.40 & 9.50 & 10.90 & 12.80 & 14.80 & 18.30 \\
\hline 504 & 7.30 & 10.90 & 12.70 & 14.30 & 16.30 & 20.10 \\
\hline 576 & 8.50 & 12.10 & 13.50 & 15.90 & 17.70 & 21.80 \\
\hline 648 & 9.30 & 14.10 & 14.90 & 17.40 & 18.50 & 23.70 \\
\hline 720 & 9.10 & 14.30 & 14.80 & 17.30 & 18.30 & 23.50 \\
\hline
\end{tabular}

*All data are representative as means of three repeated determinations. 


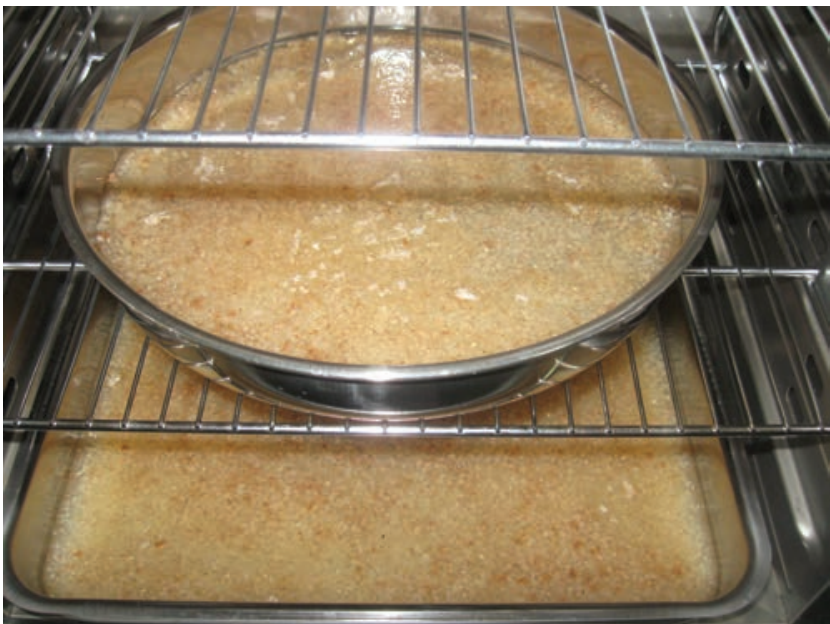

Figure 2. Biocompost obtained through the bioconversion of apple wastes by using the co-cultures of $B$. subtilis and $P$. ostreatus.

\section{Discussion}

Analysing the registered data, it was revealed the fact that by applying this biotechnology, the fruit wastes can be recycled as useful raw materials for mushroom growing in order to get significant mushroom biomass production in contrast with actual composting techniques that are not suitable to control and monitor the microbiological and chemical qualities of the final products of fruit waste bioconversion process as reported by Chahal (1994) and Smith (1998).

Thus, it can be noticed that the optimal temperatures for both bacteria and mycelia cultures to produce microbial biomass through controlled submerged fermentation as mono- and co-cultures, were registered between $23-25^{\circ} \mathrm{C}$, corresponding to initial $\mathrm{pH}$ levels of 4.5-6.0 and the agitate-on speed was tested in the range of $30-90 \mathrm{rpm}$.

The amounts of nitrogen concentration as a chemical marker of protein biomass synthesis through bioconversion of apple and plum wastes by using co-cultures of $B$. subtilis and $P$. ostreatus contained between 28.1 and $30.3 \mathrm{~g} \%$ dry weight after $720 \mathrm{~h}$ of submerged fermentation in the culture vessel of the laboratory-scale bioreactor.

The registered results revealed an increasing of reducing sugars correlated with an increasing of protein content analysed as total nitrogen for the microbial biomass of co-cultures, in comparison with the control samples represented by the monocultures of the same bacterial and fungal species used in experiments.

\section{Conclusions}

The microbial strains of $B$. subtilis and $P$. ostreatus were used in pairs as well as separately to compare the efficiency of their biological potential in bioconversion of fruit wastes into protein biomass. These strains were tested both in monocultures and co-cultures for growing on two variants of culture substrates made of apple and plum wastes mixed with cereal wastes.

The optimal temperatures for both bacteria and mycelia cultures to produce microbial biomass through controlled submerged fermentation as mono- and co-cultures, were registered between $23-25^{\circ} \mathrm{C}$,

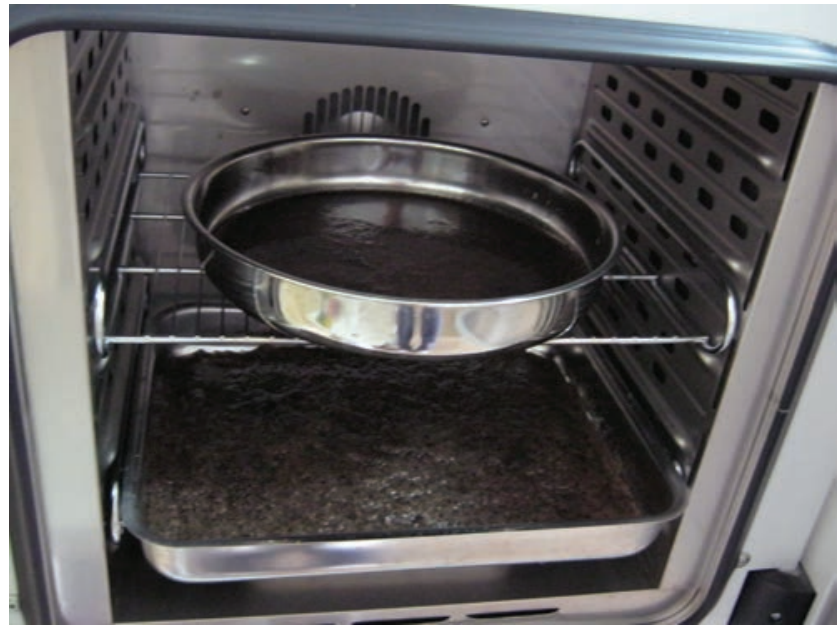

Figure 3. Biocompost obtained through the bioconversion of plum wastes by using the co-cultures of $B$. subtilis and $P$. ostreatus.

corresponding to initial $\mathrm{pH}$ levels of 4.5-6.0 and the agitation speed was tested in the range of $30-90 \mathrm{rpm}$.

The registered results revealed an increasing of reducing sugars correlated with the significant level of protein content analysed as total nitrogen for the microbial biomass of co-cultures, in comparison with the control samples represented by the monocultures of the same bacterial and fungal species used in experiments.

Due to its nutritive protein content, the final biomass resulted from the biotechnological process of bioconversion of apple and plum wastes by using monocultures and co-cultures of $B$. subtilis and $P$. ostreatus is appropriate to be used as natural bio-fertilisers of horticultural crops, being produced by controlled composting of organic wastes.

\section{References}

Beguin P, Aubert JP, 1994. The biological degradation of cellulose. FEMS Microbiol. Rev. 13:25-58.

Carlile MJ, Watkinson SC, 1996. Fungi and biotechnology. In: M.J Carlile and S.C. Watkinson (eds.), The fungi. Academic Press, London, UK, pp 230-245.

Chahal DS, 1994. Biological disposal of lignocellulosic wastes and alleviation of their toxic effluents. In: G.R. Chaudry (ed.), Biological degradation and bioremediation of toxic chemicals. Chapman \& Hall, London, UK, pp 156-173.

Chahal DS, Hachey JM, 1990. Use of hemicellulose and cellulose system and degradation of lignin by Pleurotus sajor-caju grown on corn stalks. Am. Chem. Soc. Symp. 433:304-10.

Glazebrook MA, Vining LC, White RL, 1992. Growth morphology of Streptomyces akiyoshiensis in submerged culture: influence of $\mathrm{pH}$, inoculum, and nutrients. Can. J. Microbiol. 38:98-103.

Kubicek CP, Messner R, Guber F, Mach RL, 1993. The Trichoderma cellulase regulatory puzzle: From the interior life of a secretory fungus. Enzyme Microbiol. Technol. 15:90-8.

Lamar RT, Glaser JA, Kirk TK, 1992. White rot fungi in the treatment of hazardous chemicals and wastes. In: G.F. Leatham (ed.), Frontiers in industrial mycology. Chapman \& Hall, New York, NY, USA; pp 127-143. 
Leahy JG, Colwell RR, 1990. Microbial degradation of hydrocarbons in the environment. Microbiol. Rev. 54:305-15.

Moser A, 1994. Sustainable biotechnology development: from high-tech to eco-tech. Acta Biotechnol. 12:2-6.

Petre M, Petre V, 2012. The semi-solid state cultivation of edible mushrooms on agricultural organic wastes. Sci. Bull. Ser. F. Biotechnol. $16: 36-40$.

Petre M, Petre V, 2013. Environmental biotechnology for bioconversion of agricultural and forestry wastes into nutritive biomass. In: M. Petre (ed.), Environmental biotechnology - new approaches and prospective applications. InTech Open Access Publ., Rijeka, Croatia, pp 3-23.
Ropars M, Marchal R, Pourquie J, Vandercasteele JP, 1992. Large scale enzymatic hydrolysis of agricultural lignocellulosic biomass. Biores. Technol. 42:197-203.

Smith JE, 1998. Biotechnology, $3^{\text {rd }}$ ed. Cambridge University Press, Cambridge, UK, pp. 56-70.

Stamets P, 1993. Growing gourmet and medicinal mushrooms. Ten Speed Press, Berkeley, Toronto, Canada, pp. 390-400.

Verstraete W, Top E. 1992. Holistic environmental biotechnology. Cambridge University Press, Cambridge, UK, pp. 35-43.

Wainwright M. 1992. An introduction to fungal biotechnology. John Wiley \& Sons, Chichester, UK, pp. 56-70. 